\title{
A CROSS SECTIONAL STUDY OF AETIOLGY OF ANAEMIA IN ADOLOSCENT GIRLS PRESENTING TO A TERITIARY CARE HOSPITAL
}

J. C. Panchasheelan, Ravikumar. V, Ravikumar. R, T. Anilkumar, N. Satyanarayana, Jaykumar.

1. Assistant Professor, Department of General Medicine, ESIC. MC, PGIMSR, Rajajinagar, Bangalore.

2. Assistant Professor, Department of General Medicine, ESIC. MC, PGIMSR, Rajajinagar, Bangalore.

3. Post Graduate, Department of General Medicine, ESIC. MC, PGIMSR, Rajajinagar, Bangalore.

4. Professor \& HOD, Department of General Medicine, ESIC. MC, PGIMSR, Rajajinagar, Bangalore.

5. Associate Professor, Department of General Medicine, ESIC. MC, PGIMSR, Rajajinagar, Bangalore.

6. Assistant Professor, Department of General Medicine, ESIC. MC, PGIMSR, Rajajinagar, Bangalore.

\section{CORRESPONDING AUTHOR}

Dr. Anil Kumar. T,

Professor and HOD,

Department of General Medicine

ESIC MC PGIMSR, Rajajinagar, Bangalore,

E-mail: buddhatozen@yahoo.co.in

Ph: 00919482524500

ABSTRACT: Anaemia is a very common problem in our country and iron deficiency is the most common cause especially in the adolescent age group of girls .Auto-immune haemolytic anaemia (AIHA) is an acquired type of haemolytic anaemia, caused by autoantibodies directed against the red cells. We hereby report a cross sectional study of chronic severe anaemia, which presented to our hospital for evaluation.5 patients of the 36 patients evaluated over a period of 3 months were found to have a haemolytic anaemia. 2 patients had beta thalassemia minor and 3 patients had autoimmune haemolytic anaemia with warm antibodies. Treatment with prednisolone resulted in significant improvement of the haematological parameters in these 3 patients along with blood transfusion. Alternative aetiological causes of anaemia should be considered in patients with microcytic hypochromic anaemia for proper management of patients.

KEYWORDS: Adolescent Girls, iron deficiency, haemolysis, blood transfusion, corticosteroids.

INTRODUCTION: The problem of anaemia in adolescence girls is $56 \%$ as per the UNICEF report in 2010.UNICEF has instituted an Adolescent girls anaemia programme in view of the gravity of the problem ${ }^{1}$. Iron deficiency is the most common cause of anaemia in women especially in the age group of 20 to 45 years. This is due to menstrual blood loss, low bioavailability diet, poverty and ignorance of proper diet. Poor nutrition is a significant factor for the development of anaemia due to iron deficiency2. However all cases of microcytic hypochromic anaemia tend to be labelled as nutritional especially in the setting of a government hospital which renders to predominantly low socioeconomic strata and are managed with iron supplements. We made an attempt to find alternate causes of anaemia in this age group of women. EMPLOYEES STATE INSURANCE medical college is a referral hospital and most of the referrals are for blood transfusions with severe anaemia and a provisional diagnosis of iron deficiency anaemia. We felt a need to study the aetiological factors of anaemia other than iron deficiency for better management strategies 
Auto Immune Haemolytic anaemia (AIHA) is the clinical condition caused by autoantibodies, which bind to the red cell surface resulting in extravascular haemolysis. AIHA are classified into warm AIHA, cold AIHA, mixed type and drug induced type. Warm antibody type accounts for $70 \%$ of all AIHA. It is of Ig G type and usually does not fix the complement. AIHA can be a primary disorder (50\%) or secondary to lymphoproliferative diseases, other systemic autoimmune diseases, viral infections, immune deficiency states, etc. Direct Coomb's test which detects Ig and/or Complement bound to the surface of the red cell is the diagnostic test for $\mathrm{AIHA}^{3}$. Beta thalassemia is a hereditary haemolytic anaemia Detection usually involves lower than normal MCV value ( $<80 \mathrm{fL}$ ). Plus an increase in fraction of Haemoglobin A2 $(>3.5 \%)$ and a decrease in fraction of Haemoglobin $\mathrm{A}(<97.5 \%)$.

MATERIAL AND METHODS: All women in the age group of 15 to 25 years with a haemoglobin of less than 6 gms per deciliter and admitted in the female medical ward of ESI MEDICAL COLLEGE hospital over a period of 3 months were included in the study .We included patients who were referred for blood transfusion and had microcytic hypochromic anaemia.. We excluded pregnant women and those with past pregnancy and child birth. We also excluded women with comorbid medical illness such as tuberculosis, connective tissue disorders and malignancies. We also excluded patients with obvious blood loss.

The patients were asked a detailed history with special reference to blood loss, drug intake, connective tissue disorders and malignancies. They underwent a detailed medical examination with special emphasis on detecting the previously mentioned diseases.

The complete haemogram of all the patients was analysed. The subgroup of 5 patients with increased reticulocyte count, increased indirect bilirubin and increased reticulocyte index $(>3)$ were subjected to tests of haemolysis such as Coombs test, lactate dehydrogenase and serum haptoglobulin. They were also subjected to viral serological tests such as HBsAg, HIV, Epstein Barr Virus Capsid antigen and TORCH panel (Toxoplasma, Rubella, Cytomegalovirus and Simplex). They were also screened for antinuclear antibodies.

RESULTS: 32 Patients who satisfied the inclusion criteria were enrolled in the study.27 patients with microcytic hypochromic anaemia had all the criteria for iron deficiency. The patients with iron deficiency had low serum ferritin and increase total iron binding capacity .5 out of the 32 patients had markers of haemolysis such as increased reticulocyte count, increased reticulocyte index, increased indirect bilirubin and reduced haptoglobin $(<6)$. The peripheral smear of these 5 patients revealed numerous spherocytes, polychromasia and nucleated red blood cells.

Two of the 5 patients had beta thalassemia minor on haemoglobin electrophoresis with a haemoglobin A2 level of more than 3\%.In the remaining three patients directs Coombs test was positive at room temperature and 37 degree and indirect Coombs test was negative. A diagnosis of warm antibody immune haemolytic anaemia was made based on these findings in these 3 patients.

The patients with iron deficiency anaemia and beta thalassemia were treated with blood transfusions and iron supplements in appropriate cases. Deworming with albendazole in standard doses was done. The three patients with a diagnosis of warm antibody haemolytic anaemia were put on prednisolone at the dose of $1 \mathrm{mg}$ per $\mathrm{kg}$ body weight and showed a dramatic improvement in their haemoglobin levels. There was a reduction in the haemolytic parameters such as lactic dehydrogenase and reticulocyte index. 
DISCUSSION: The incidence of iron deficiency in adolescent girls in our study is very high with over $80 \%$ patients in this category. In a nationwide survey reported by Ramesh Chellan and Lopamudra Paul nearly $90 \%$ had iron deficiency anaemia in the adolescent age group 4 .

The frequency of beta thalassemia was $6 \%$ in our population .The frequency of beta thalassemia was 3-5\% in a study done by SS Ambekar et all in Maharashtra with beta minor accounting for $21 \%$ of cases in adults ${ }^{5}$. In a study done by P LAHARI et all the incidence of beta thalassemia was found to be very high in the Indian population ${ }^{6} .6 \%$ of our patients had AIHA with severe anaemia and markers of haemolysis. Vanamala et all in their study found that AIHA a predilection to female and was prone for severe anaemia necessitating blood transfusion? Choudary et all in their study demonstrated a good response to corticosteroids in patients with AIHA $^{8}$. Ganty et all in their study found $51 \%$ of their patients to have a primary AIHA after screening for malignancies and connective tissue disorders 9 .

CONCLUSION: All cases of microcytic hypochromic anaemia need to be evaluated in detail so as to detect autoimmune haemolytic anaemia. Special attention need to be paid to patients presenting with severe anaemia, recurrent anaemia and with no obvious blood loss history. The lab parameters of haemolysis such as lactic dehydrogenase, reticulocyte index and serum haptoglobin along with the Coombs test are especially useful in the diagnosis of warm antibody autoimmune haemolytic anaemia. The diagnosis of AIHA will alter the management of anaemia in the sense that they are responsive to corticosteroids and with blood transfusion will result in rapid improvement of anaemia.

ACKNOWLEDGMENTS: We acknowledge Dr Manjula. M for her necessary support. We also thank Dr Vedha. P, Department of pathology for her necessary help.

\section{REFERENCES:}

1. Accelerating efforts to advance the rights of adolescent girls: A joint United Nations Statement; ILO, UNESCO, UNFPA, UNICEF, UNIFEM and WHO, 2010.

2. Diet and nutritional status of adolescent tribal population in nine states of India Rao KM, Balakrishna N, Laxmaiah A, Venkaiah K, Brahmam GN Asia Pac J Clin Nutr. 2006;15(1):64-71

3. Autoimmune haemolytic anaemia: pattern of presentation and management outcome in a Nigerian population: a ten-year experience. Afr J Med Med Sc. 2002 Jun;31(2):97-100.

4. Prevalence of Iron-Deficiency Anaemia in India: Results from a Large Nationwide Survey Ramesh Chellan Lopamudra Paul Journal of Population and Social Studies Volume 19 Number 1

5. Pattern of Hemoglobinopathies in Western Maharashtra Ambekar M.A.PhadkeG.D. Mokash Indian Pediatrics 2001; 38: 530-534

6. Understanding Beta-Thalassemia with Focus on the Indian Subcontinent and the Middle East P. Lahiry S.A. Al-Atta and R.A. Hegele*The Open Hematology Journal, 2008, 2, 5-13

7. Clinical Patterns and Haematological Spectrum in Autoimmune Haemolytic Anemia Vanamala Alwar, Devi A M Shanthala, S Sitalakshmi, and R K Karuna J Lab Physicians. 2010 Jan-Jun; 2(1): 17-20

8. Clinico-hematological spectrum of auto-immune haemolytic anemia: an Indian experience Choudhry VP, Passi GR, Pati HP J Assoc Physicians India.1996 Feb;44(2):112-4

9. Characteristics of autoimmune haemolytic anaemia in adults: retrospective analysis of 83 cases Genty I, Michel M, Hermine O, Schaeffer A, Godeau B, Rochant H Rev Med Interne. 2002 Nov;23(11):901-9 


\section{ORIGINAL ARTICLE}

\section{AETIOLOGY OF ANAEMIA IN OUR STUDY-TOTAL 32 PATIENTS}

\begin{tabular}{|l|l|l|l|}
\hline Serial number & Disease & number & Percentage \\
\hline 1 & $\begin{array}{l}\text { BETA THALASSEMIA } \\
\text { MINOR }\end{array}$ & 2 & $6 \%$ \\
\hline 2 & AIHA & 3 & $9 \%$ \\
\hline 3 & IRON DEFICIENCY & 27 & $85 \%$ \\
\hline
\end{tabular}

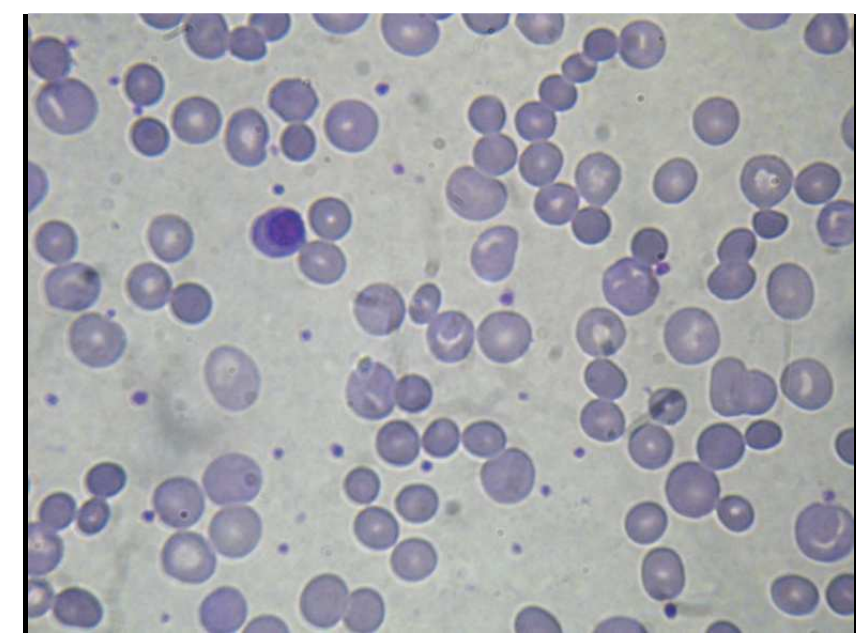

Figure 1 .peripheral smear showing spherocytes, one Normoblast and Polychromasia

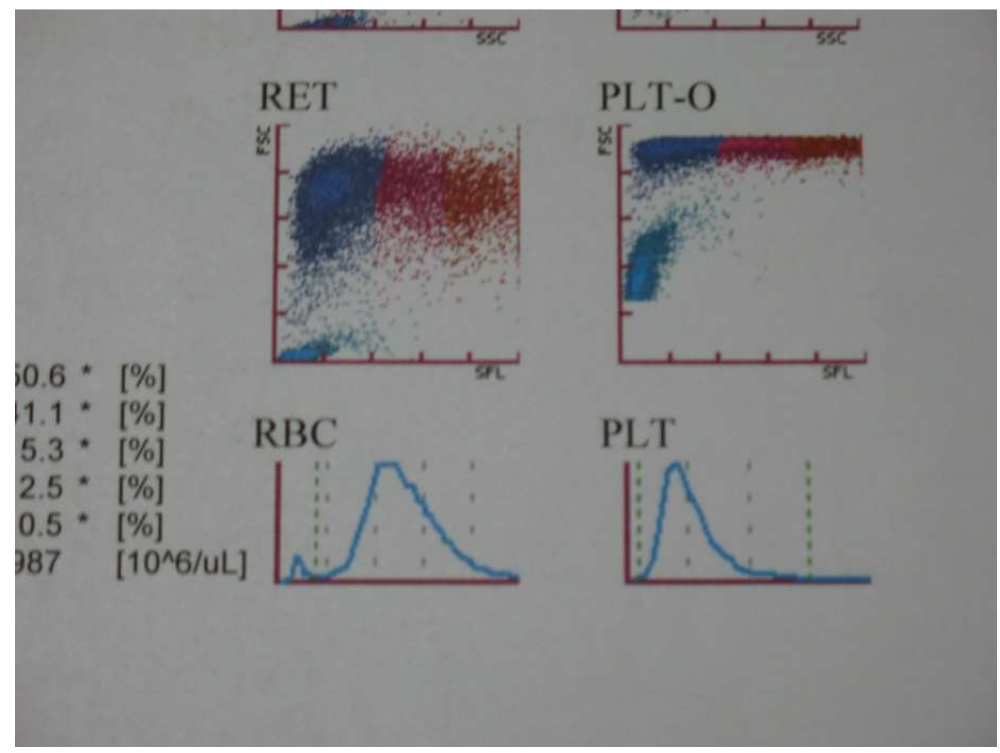

Figure 1 Hemogram showing marked reticulocytosis 


\section{ORIGINAL ARTICLE}

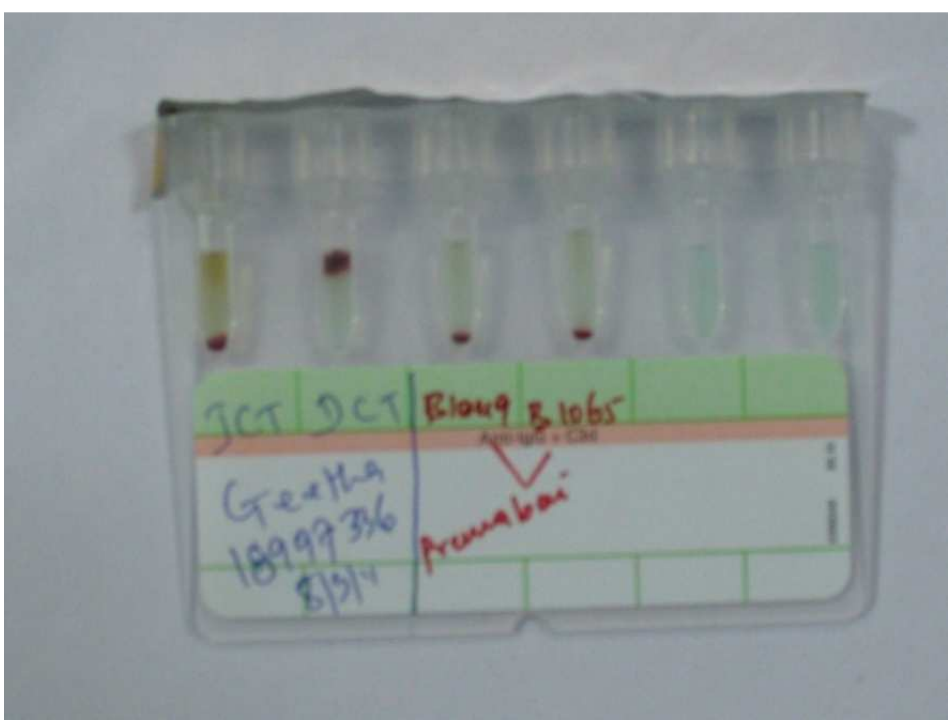

Figure 2. Positive Direct Coomb,s test 